\title{
FAILURE ANALYSIS OF ALUMINO THERMIC WELDED RAIL
}

\author{
A.M.Tripathi ${ }^{1}$ and Ram Jatan Yadav $^{2}$
}

\begin{abstract}
With the increasing speed, heavier axle loads, mixed type of traffic, added with rail manufacturing defects, not following welding procedures in total and poor maintenance standards, the service life of rails has been drastically reduced. Many premature rail renewals have been done in the recent years on Indian railways due to rail failures in large numbers. Rail is the backbone of track structure and it should be protected from any defect, so that it can live its service life.

The Rails account for large proportion (from 30\%-50\%) of the cost of new infrastructure. Management of this asset, its maintenance and its renewal costs play a key role in the optimization of track maintenance cost. Rail is the components which are directly subject to stresses and undergo direct wear by rolling stock. Fatigue and fracture of rails is a rather complex issue. It has to be distinguished between rails in straight and curved track sections, rails of tracks which are operated in one or in both directions rail butt welds, switches, etc.

Rail fracture taking place nowadays becomes severe problem for rail manufacturer and users both. Starting from manufacturing defects upto the environmental conditions there are so many parameters which are governing the rail fracture for new rail as well as welded rail. In this case failure analysis gives us the guidelines to avoid such failure of rails and also to overcome such phenomenon again and again.

Present paper discussed about an AT welded rail which was failed during service. There are two samples taken first one has completed a service life of $\mathbf{1 . 5}$ months and other 3 months.

Key words - Fracture, welded rails, HAZ
\end{abstract}

\section{INTRODUCTION}

Metallurgical investigations have been used in the last decades to overcome failure of railway components. A metallurgical investigation was carried out on the railway rails after they were failed. The rails were made of high carbon steel having ferritic- pearlitic microstructure and failed during the service. The testing is conducted in a laboratory according to the IRS: T-12/2009. The material of the rail was specially developed 880 UTS rail and was continuously casted and heat treated before service. The present paper reports the investigation into cause of failure of railway rails.

\section{MATERIALS AND EXPERIMENTAL PROCEDURES}

The samples used in the investigation were the two pairs of fractured railway cross rails. Figure 1 shows both the rail pieces along the fracture line. Longitudinal specimens were gas cut from one piece of rail for tensile and hardness test at room temperature.

One metallographic sample was cut from both the samples for microstructure observation under an optical microscope. The sample was ground, polished, and finally etched in $2 \%$ nitric alcohol solution.

\footnotetext{
${ }^{1}$ Research Scholar, Department of Mechanical Engineering, IIT(ISM) Dhanbad, India

${ }^{2}$ Assistant Professor, Department of Mechanical Engineering, JIMS Engineering technical campus, Greater Noida, India
} 


\section{VISUAL EXAMINATION}

Visual examination of Sample Nos.1\&2 revealed that both rails had cracked longitudinally through web fig (1\&2) at rail weld joint. Total length of crack was about $150 \mathrm{~mm}$ in sample no. 1 and about $78.5 \mathrm{~mm}$ in sample no.2.

Cracks were opened \& topography of fracture face revealed crystalline fracture initiated from weld portion in both cases fig ( $3 \& 4)$.

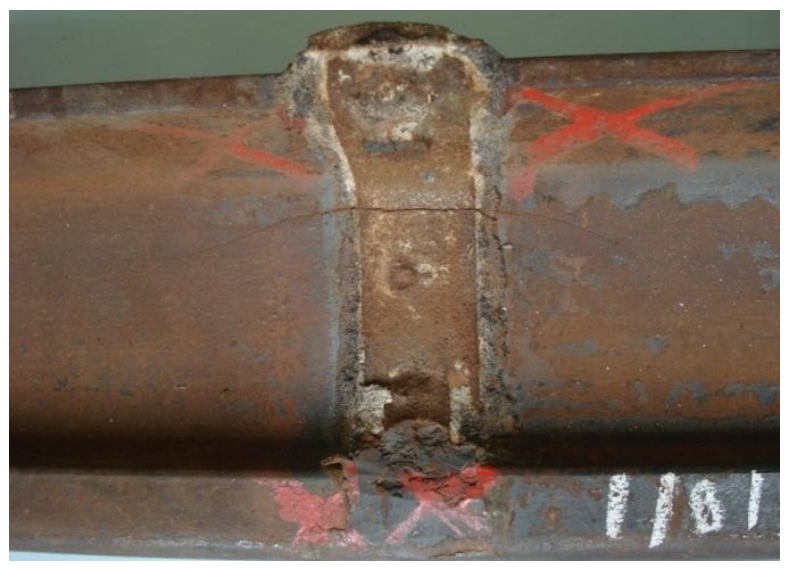

Fig.1Photograph showing location of crack in sample no.1

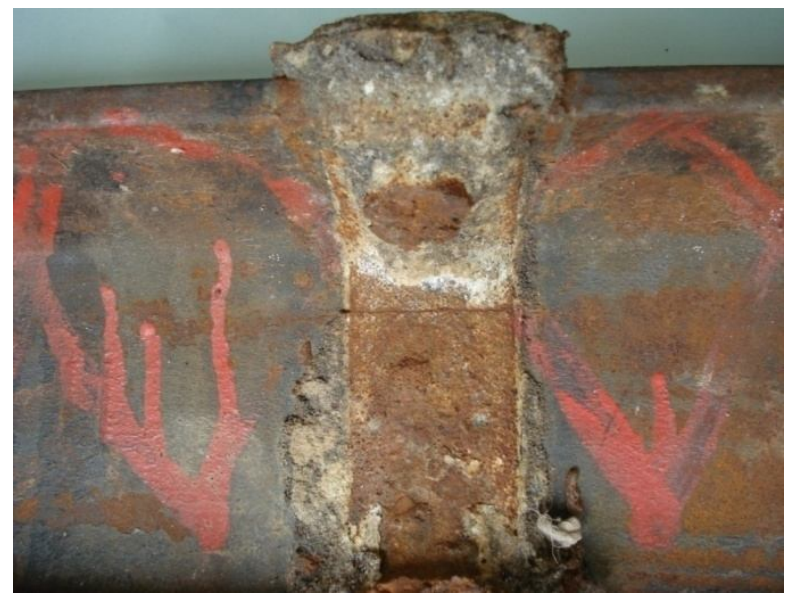

Fig.2 Photograph showing location of crack in sample no.2

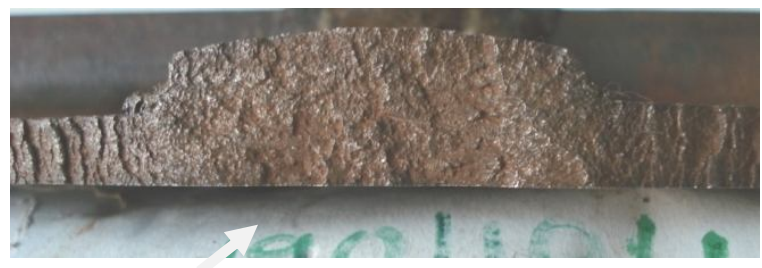

Fig.3 Fracture face of sample no.1. 


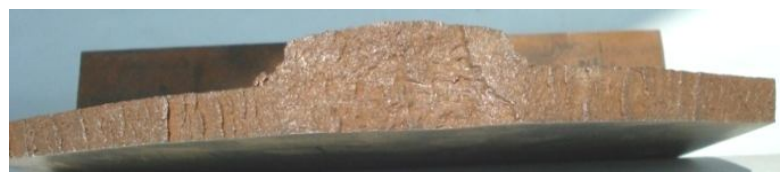

Fig.4 Fracture face of sample no.2.

\section{CHEMICAL COMPOSITION}

\begin{tabular}{|l|l|l|l|l|l|l|l|l|l|}
\hline Sample No. & $\mathbf{\%} \mathbf{C}$ & $\mathbf{\%} \mathbf{M n}$ & $\mathbf{\%} \mathbf{S i}$ & $\mathbf{\%} \mathbf{S}$ & $\mathbf{\% P}$ & $\mathbf{\%} \mathbf{M o}$ & $\mathbf{\% A l}$ & $\mathbf{\%} \mathbf{C r}$ & $\mathbf{\% V}$ \\
\hline 1(Parent Rail1) & 0.69 & 1.20 & 0.22 & 0.013 & 0.024 & - & - & - & - \\
\hline 2(Parent Rail2) & 0.71 & 1.20 & 0.27 & 0.022 & 0.035 & - & - & - & - \\
\hline Specified as per IRS T- & $0.60-$ & $0.80-$ & $0.10-$ & 0.035 & 0.035 & - & - & - & - \\
$12 / 2009$ & 0.80 & 1.30 & 0.50 & Max & Max & & & & \\
\hline 1 (Weld) & $\mathbf{0 . 4 3}$ & $\mathbf{1 . 4 9}$ & $\mathbf{0 . 5 7}$ & 0.030 & $\mathbf{0 . 1 0}$ & 0.005 & 1.24 & 0.12 & 0.17 \\
\hline 2(weld) & $\mathbf{0 . 4 1}$ & $\mathbf{1 . 5 0}$ & $\mathbf{0 . 7 0}$ & 0.034 & $\mathbf{0 . 1 1}$ & 0.005 & 1.21 & 0.12 & 0.19 \\
\hline $\begin{array}{l}\text { Specified as per IRS T- } \\
\text { 19/94, Add. \& Corr. Slip } \\
\text { No. 10/08 for 90 UTS }\end{array}$ & $0.5-$ & $0.80-$ & 0.50 & 0.05 & 0.05 & $0.10-$ & $0.05-$ & 0.2 & $0.10-$ \\
Rail & & & & & & & & & \\
max. & & & & & & & & \\
\hline
\end{tabular}

\section{HARDNESS TEST}

A longitudinal section containing weld \& heat affected area was subjected for hardness test at different locations. The observations made are under:

\begin{tabular}{|c|c|c|c|}
\hline $\begin{array}{l}\text { Sample } \\
\text { No. }\end{array}$ & Location & $\begin{array}{l}\text { Observations, BHN } \\
\text { (3000Kg/10mm/15secs) }\end{array}$ & Specified as per IRS:R-19/94 \\
\hline \multirow[t]{3}{*}{1} & Parent metal & $245,246,240$ & 260 (Desirable as per T-12/96) \\
\hline & HAZ & $285,286,280$ & \pm 20 of actual parent metal \\
\hline & Weld & 313,317 & $\begin{array}{l}+20 \text { (Max) } \\
-0 \text { parent metal }\end{array}$ \\
\hline \multirow[t]{3}{*}{2} & Parent metal & 252,253 & 260 (Desirable as per T-12/96) \\
\hline & HAZ & 293,285 & \pm 20 of actual parent metal \\
\hline & Weld & $315,307,309$ & $\begin{array}{l}+20 \text { (Max) } \\
-0 \text { parent metal }\end{array}$ \\
\hline
\end{tabular}

\section{MACRO EXAMINATION}

Longitudinal slices of each rail sample were nital etched, different zones were observed in both the rail pieces. No abnormality was revealed in both cases. 


\section{MICRO EXAMINATION}

Micro pieces containing the crack initiation zone were examined under microscope.

\begin{tabular}{|l|l|l|}
\hline Sample No & Location & Observation \\
\hline \multirow{3}{*}{1} & Parent rail & $\begin{array}{l}\text { Revealed pearlite within thin and broken network of ferrite at places } \\
\text { (fig.5). }\end{array}$ \\
\cline { 2 - 3 } & Weld & $\begin{array}{l}\text { Revealed cast columnar grains of pearlite with in ferrite network } \\
\text { with dispersed ferrite (fig.6). }\end{array}$ \\
\cline { 2 - 3 } & HAZ & $\begin{array}{l}\text { Revealed coarse pearlite within thin and broken network of ferrite. } \\
\text { (Fig6). }\end{array}$ \\
\hline
\end{tabular}

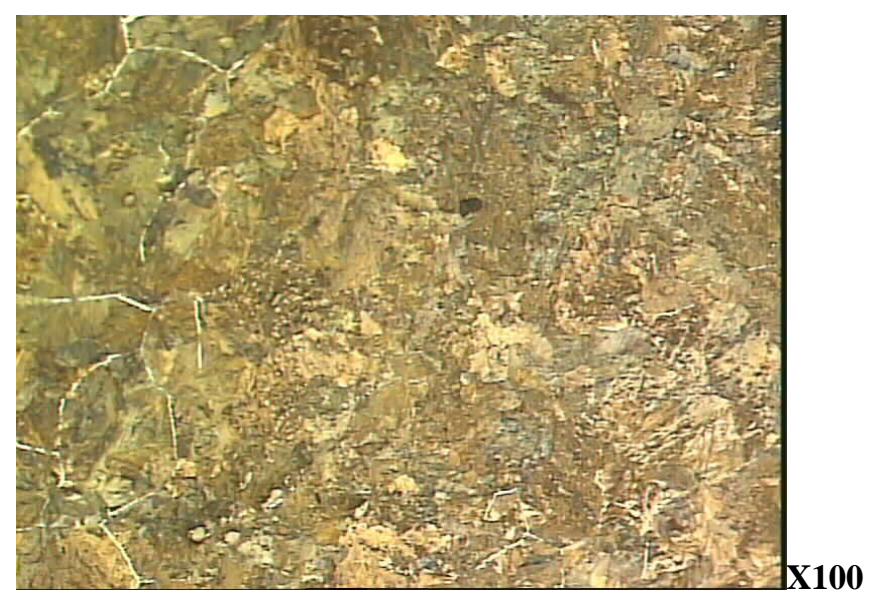

Fig-5 Photomicrograph of parent rail showing pearlite within thin and broken network of ferrite at places.

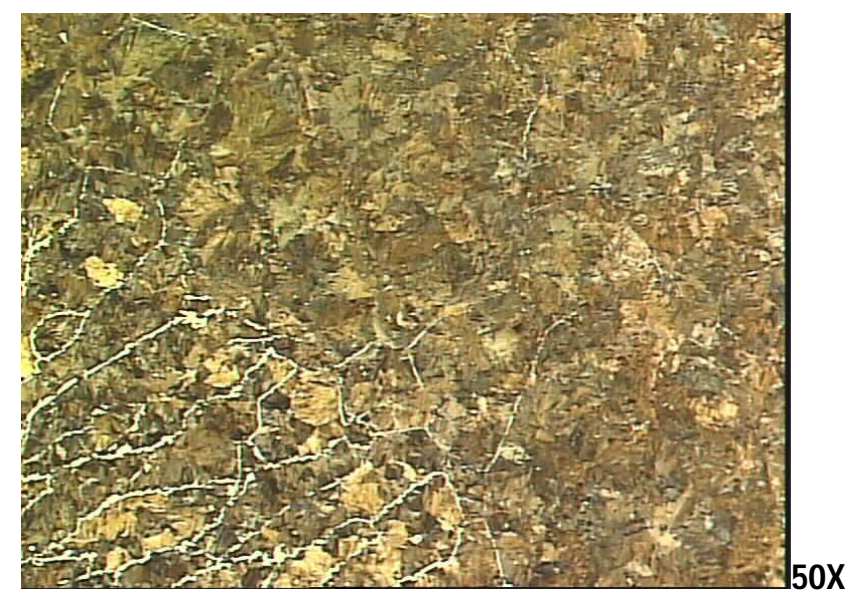

Fig-6 Photomicrograph showing weld and HAZ.

\begin{tabular}{|l|l|l|}
\hline $\begin{array}{l}\text { Sample } \\
\text { No }\end{array}$ & Location & Observation \\
\hline \multirow{4}{*}{2} & Parent rail & Revealed pearlite within thin and broken network of ferrite.(fig7) \\
\cline { 2 - 3 } & Weld & $\begin{array}{l}\text { Revealed cast columnar grains of pearlite with in ferrite network with } \\
\text { dispersed ferrite (fig.8). }\end{array}$ \\
\cline { 2 - 3 } & HAZ & Revealed coarse pearlite within thin network of ferrite. (Fig.8). \\
\hline
\end{tabular}




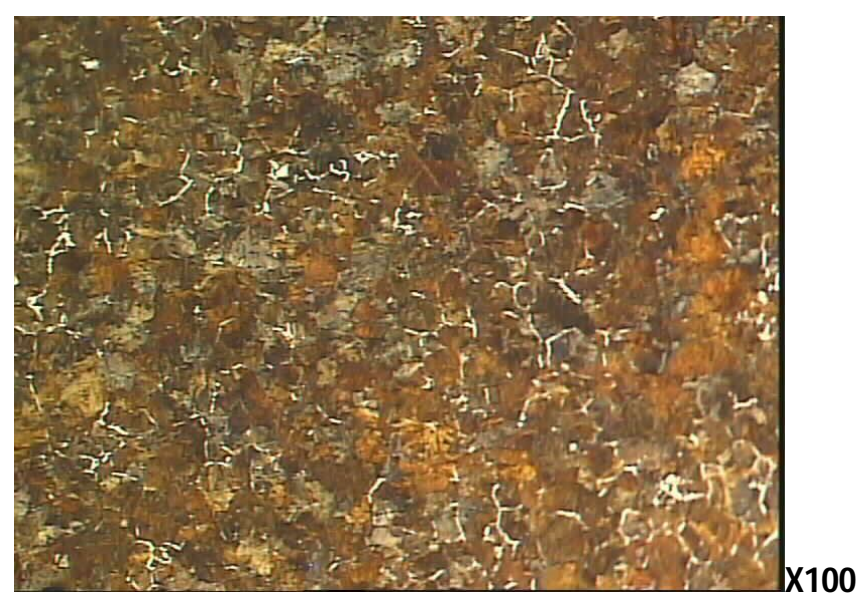

Fig.7 Photomicrograph of parent rail showing pearlite within thin and broken network of ferrite.

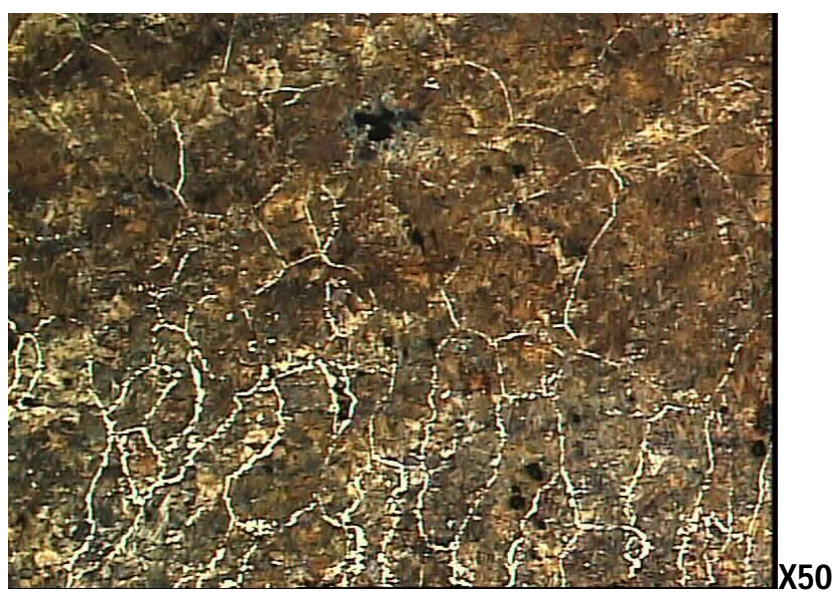

Fig-8 Photomicrograph showing weld and HAZ.

\section{DISCUSSION}

Sample No. 1

Visual examination of Sample No.1 revealed that rail had cracked longitudinally through web at rail weld joint \& total length of crack was about $150 \mathrm{~mm}$. Chemical composition of rail conforms to relevant specification. Chemical composition of weld does not conform to the specification in terms of lower $\% \mathrm{C}$, higher $\% \mathrm{Mn}, \% \mathrm{Si} \& \% \mathrm{P}$. Hardness values of rail are lower than desirable. Hardness values of weld \& HAZ are higher than specified.

\section{Sample No. 2}

Visual examination of Sample No.2 revealed that rail had cracked longitudinally through web at rail weld joint \& total length of crack was about 78.5 $\mathrm{mm}$. Chemical composition of rail conforms to relevant specification. Chemical composition of weld does not conform to the specification in terms of lower $\% \mathrm{C}$, higher $\% \mathrm{Mn}$, $\%$ Si \& \%P. Hardness values are lower than desirable. Hardness values of weld \& HAZ are higher than specified. 
Higher percentage of $\mathrm{Si} \& \mathrm{P}$ in both cases has made the weld pool brittle. The hardness of AT weld \& HAZ being on higher side shows faster cooling of the weld joint which means an earlier removal of mould resulting in air contact of weld pool and its faster cooling. In this situation the weld is likely to have very high level of residual stresses. This high level of residual stresses had fractured the rail longitudinally across the weld in web portion.

\section{CONCLUSION}

$$
\text { Sample No. } 1 \& 2
$$

The sudden failure of AT weld joint may be attributable to use of wrong portion in terms of chemistry \& early removal of mould resulting in high level of residual stresses.

\section{REFERENCES}

[1]. Y.Gao, Z.J. Zheng, H.W.Dong, M.Q.Zeng, M Jhu, Analysis on the Rupture Failure of Railway Cross Rails, J Fail. Anal. and Preven. (2007) 7:330-335 DOI 10.1007/s11668-007-9059-8

[2]. John Ade Ajayi, O.A. Adeleke, Failure Analysis of Railway Brake Blocks,

[3]. R. Fuoco, M.M. Ferreira, C.R.F. Azevedo, Failure analysis of a cast steel railway wheel, Engineering Failure Analysis 11 (2004) 817-828

[4]. IRS: T-12/2009 Indian railway specification.

[5]. ASM Handbook volume-11 Failure Analysis and Prevention p-840 